\title{
Influence of joint clearance on kinematic and dynamic parameters of mechanism
}

\author{
C. A. Akhadkar ${ }^{1}$, A. B. Deoghare ${ }^{2,}$ A. M. Vaidya ${ }^{3}$ \\ ${ }^{\text {I}}$ (Research Scholar, Mechanical Engineering Department, GH Raisoni College of Engineering, Nagpur, India) \\ ${ }_{2}^{2}$ (Professor, Mechanical Engineering Department, GH Raisoni College of Engineering, Nagpur, India) \\ ${ }^{3}$ (Principal, KVN College of Engineering, Nashik, India)
}

\begin{abstract}
Kinematic joints for dynamic analysis of multi-body mechanical systems assumed ideal or perfect. However, in a real mechanical kinematical joint clearance is always present. Such clearance is necessary for the component assemblage and to allow the relative motion between the connected bodies. This clearance is inevitable due to the manufacturing tolerances, material deformations, wear, and imperfections. The presence of such joint clearance degrades the performance of mechanical systems in virtue of the contact and impact forces that take place at the joint. Contact analysis is a computational bottleneck in mechanical design where the contact changes. Manual analysis is time-consuming and prone to error. To address these problems, a geometrical contact analysis method based on kinematic simulation, using CAD software is developed. An equivalent kinematic linkage mechanism is constructed according to contact position of pin and hole assembly. Results of kinematic and dynamic analysis of a four bar linkage with joint clearance shows that the contribution of joint forces at slower input speed also degrades the performance of mechanism.
\end{abstract}

Keywords: Clearance link, equivalent mechanism, joint forces, degree of freedom.

\section{Nomenclature}

Length of link (mm), $L_{i}$

Angular position of links $\left(^{\circ}\right), \theta i$

Clearance link at joint (mm), $C_{l i}$

Angular position of clearance links $\left({ }^{\circ}\right), \psi_{i}$

Length of equivalent link (mm), $L_{e i}$

Angular position of equivalent links $\left({ }^{\circ}\right), \boldsymbol{\varphi}_{i}$

Angular velocity $(\mathrm{rad} / \mathrm{sec}), \omega$

Angular Acceleration $\left(\mathrm{rad} / \mathrm{sec}^{2}\right), \dot{\omega}$

Joint Force (N), $F$

Clearance (mm), $c$

Number of links, $N$

Density $\left(\mathrm{kg} / \mathrm{m}^{3}\right), \rho$

Poisson's Ratio, $v$

Young's Modulus $\left(\mathrm{kg} / \mathrm{m}^{2}\right), E$

\section{Introduction}

Ideal revolute joint has only one axial rotational degree of freedom. It is a common and unconstrained axis of the revolute joint. In a 3-D revolute clearance joint, one degree of freedom added between pin and hole assembly. Such assembly is under presence of different external forces such as contact, impact, friction, gravity etc. In this study pure contact method is addressed. The position of contact point during the rotation of linkages is unpredictable. Exact position is extracted from the 2-D constraint simulation of the four bar mechanism with clearance joint. Exact contact position gives the instantaneous maximum clearance between pin and hole. It is a geometrical approach to extract the contact point. A mass-less clearance link is constructed, which gives the instantaneous equivalent mechanism. Analysis of set of such instantaneous equivalent mechanism gives the variation in kinematic and dynamic parameters.

The performance deviation due to clearance in joint was addressed in previous work with different methodology. A geometrical model was used to explain and assess the output position or direction variation, to predict the limit of position uncertainty and to determine the maximum clearance. [1] A four-bar mechanism having two joints with clearance was considered as a model mechanism. A neural network was used to model several characteristics of joint clearance. Kinematic and dynamic analyses were achieved using continuous contact mode between journal and bearing. Kinematic analysis of the model mechanism comprises determining of displacements, velocities and accelerations of the mass centers of moving links. Loop closure equation from the vector representation of the clearance link was used for the analysis. [2] Equations are derived that describes 
the condition of clearance revolute joint without considering the hydrodynamic lubrication. The equations are governed by dimensionless parameter that depends on nominal motion, mass distribution and influence coefficient of the linkage in which the joint appears with clearance. [3]

There are four sub cases of contact configurations. These are no contact, one point contact, two points contact, and line contact. There are four main modeling strategies for mechanical systems with revolute clearance joints, namely, the mass-less link approach, the spring-damper approach, the momentum exchange approach and FEM approach. Equations of motion of plane multilink mechanism with clearances were constructed by Hiroaki in 1978. Two joints with clearances and pure contact of a four bar mechanism were considered. [4] Typical contact-impact force models with dissipated effects are dependent on the contact velocities, and therefore, it is important to evaluate these velocities in order to account for the dissipative effects during the contact-impact process. [6] It has been observed that, in single loop linkage, joint clearances with same value contribute equally to deviation of the link from its ideal position. It is possible to assess the output position or direction variation, due to clearances allocated at the joints, by using geometrical model. [8]

In this study, 2-D kinematic four bar mechanism is considered. Three joints with clearance are simulated for the additional degree of freedom occurred due to clearances in CAD software. Max clearance of $0.5 \mathrm{~mm}$ at the joint is assumed for the analysis. Twelve crank positions are considered for the study. The clearance link is constructed according to the contact position between pin and hole bearing surface of link. Equivalent linkage is constructed for twelve position and angular position for clearance link $(\psi)$ and equivalent link $(\varphi)$ is determined. Ideal four bar mechanism and set of twelve equivalent mechanisms are kinematically and dynamically analyzed in multi-body dynamic analysis software. The variation in angular velocity and angular acceleration of all four joints of ideal four bar mechanism and equivalent mechanisms were recorded. Similarly, joint forces were also recorded and compared with ideal mechanism.

Linkage parameters of proven example [13] are considered for the validation of approach used for the kinematic analysis of the four bar mechanism.

\section{Contact Position Analysis}

2.1 Joint Clearance The joint clearance is the difference of the diameters of the pin and hole of a joint. Fig-1 shows the enlarged view clearance link (c), which is a mass-less link. Minimum 20 to 30 microns clearance is required for assembly and to have relative motion between parts. In a revolute joint, joint clearance $c$ is defined as the difference between the radii of bearing and journal, $r_{B}$ and $r_{J}$, respectively. If there is no lubrication, the journal can move freely within the bearing until any contact between the two bodies take place. If the friction is negligible, the direction of joint clearance vector coincides with the direction of normal force at the contact point. When the continuous contact mode assumption between journal and bearing at each joint is considered, the clearances may be modeled as vectors which correspond to mass-less virtual links with the lengths equal to joint clearance. The clearance can be defined as,

$\left.c=r_{B}-r_{J} \ldots \ldots \ldots \ldots \ldots \ldots \ldots \ldots . . .12 .1\right]$

Each joint clearance adds additional freedom to the mechanism, and additional constraints are necessary to analyze the system. [10]

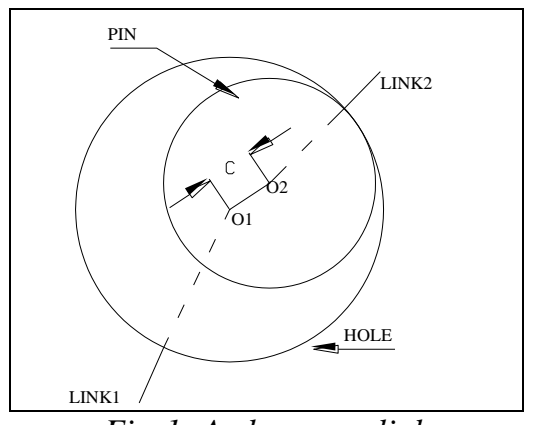

Fig-1: A clearance link

A line diagram of ideal mechanism with linkage parameters is given in fig-2. Crank, coupler and the follower are connected together and all four revolute joints are assumed perfect, i.e. without clearance. 


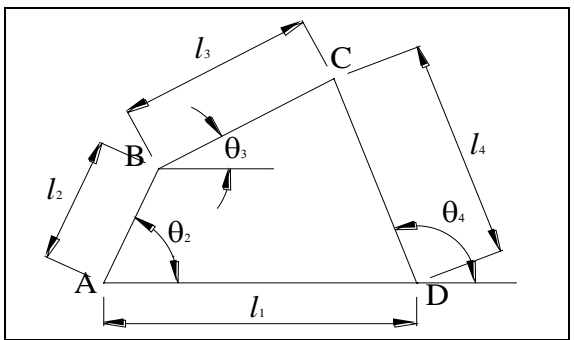

Fig-2: Linkage Parameter of Ideal four bar mechanism

Assuming constant contact between the pin and hole of a joint, a joint clearance may be modeled as a small link (called clearance link) with the length equal to one half of the joint clearance. Thus, a single degree of freedom four bar linkage would become a five degree of freedom eight bar linkage as shown in fig-3. Each joint clearance adds one degree of freedom to the linkage. The direction uncertainty due to the joint clearance is thus represented by the added redundant degree of freedom in the linkage.

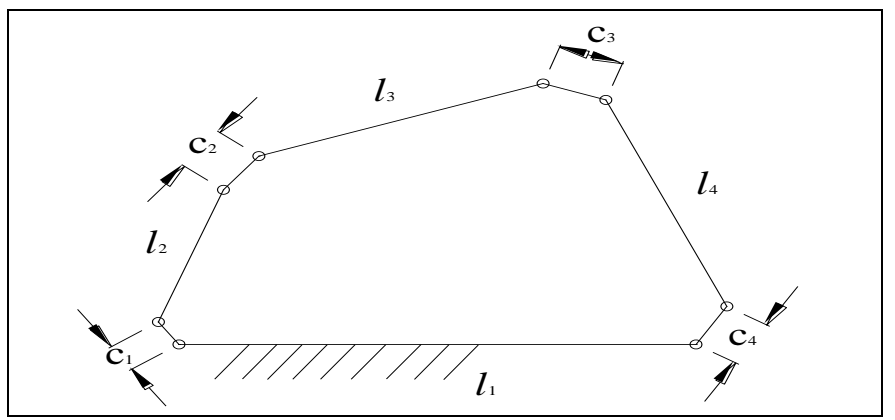

Fig-3: A eight bar linkage with joint clearance

2.2 Rotatability Laws of Linkages An ' $n$ ' degree-of-freedom linkage is defined as a fully rotatable linkage, if the linkage will never encounter a dead position, where the linkage would temporarily lose its mobility. A linkage is fully rotatable if,

1)The linkage has a class I chain

2)Each short link has an input joint on it and

3)Each input joint connects at least one short link

In a class I chain, the three longest links are called long links and the remaining links are short links. The sum of the lengths of all short links can never be greater than the length of any long link. A class I chain has the following rotatability properties.

a. Each short link can be made to have a complete rotation with respect to any link in the chain.

b. Any pair of long links can never become collinear or parallel to each other.

c. The rotation range between two long links is always less than $180^{\circ}[1]$

Let $l_{1}, l_{3}$ and $l_{4}$ be the three long links and $l_{2}$ is the short link. The angle $\theta$ between any pair of long links, say $l_{2}$ and $l_{3}$, must be in the range of $\theta_{\min } \leq \theta \leq \theta_{\max }$, where,

$\theta_{\min }=\cos ^{-1}\left\{\left[l_{1}^{2}+l_{3}^{2}-\left(l_{4}-l_{2}\right)^{2}\right] /\left(2 l_{1}+l_{3}\right)\right\}$

$\theta_{\max }=\cos ^{-1}\left\{\left[l_{1}^{2}+l_{3}^{2}-\left(l_{4}+l_{2}\right)^{2}\right] /\left(2 l_{1}+l_{3}\right)\right\}$

2.3 Rotatability of Linkages with Clearance Links Each joint clearance represented by a clearance link, an Nbar linkage is equivalent to a $(2 \mathrm{~N})$-bar linkage and the number of degree of freedom is increased from $(\mathrm{N}-3)$ to $(2 \mathrm{~N}-3)$. Because the sum of all clearance link lengths is much smaller than any nominal link length, adding clearance links does not change the classification of the resulting chain, unless the nominal linkage has a class III chain or one close to a class III chain.

If each of the $(\mathrm{N}-3)$ inputs is given between two nominal links, the equivalent linkage still has $\mathrm{N}$ degrees of freedom. The additional freedom is due to the uncertainty caused by the joint clearance. By giving random inputs to the $\mathrm{N}$ clearance links, the uncertain rotation region between nominal links can be determined. [1] 
2.4 Contact Prediction Contact points at different positions of the mechanism are determined from contact position. Similar approach is followed for all three clearance revolute joint.

A four bar mechanism is constructed in CAD software considering the constraints due to clearance and simulated for the one revolution. A joint clearance mechanism is constructed with clearance of $0.5 \mathrm{~mm}$. The mechanism is constructed with additional degree of freedom. This mechanism is kinematically simulated for additional degree of freedom. The construction is given in fig- 4 and fig- 5 for $30^{\circ}$ crank position. Contact point is marked from the kinematic position and linkage parameters of the clearance link are measured from the CAD geometry. Thus the resultant link called as equivalent link is investigated. The equivalent linkage for each position is generated and analyzed with multi-body dynamic analysis software. Similar steps are followed for the twelve crank positions in one rotation. Position of the point of contact and clearance link for one revolution in the step of $30^{\circ}$ are investigated and tabulated in table- 1 .

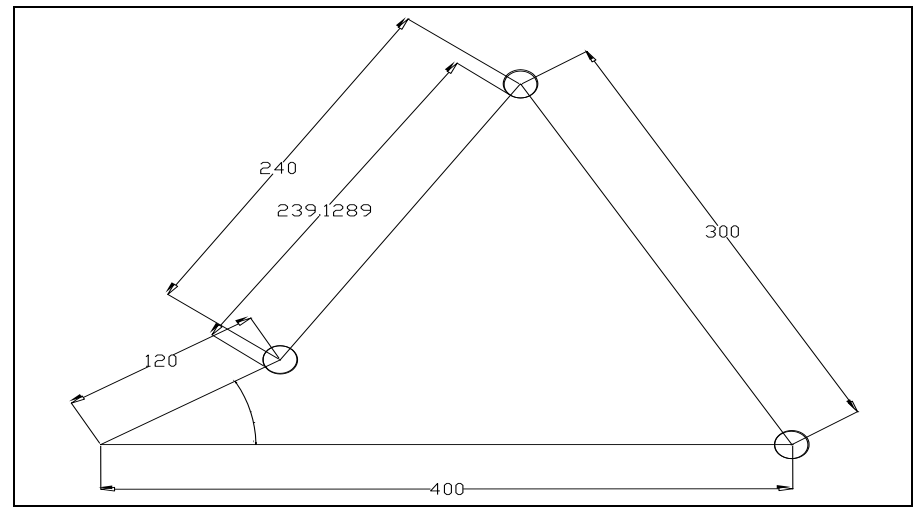

Fig-4: Contact Position of a revolute joint with clearance

Table-1 Position of Clearance link in one revolution

\begin{tabular}{|c|c|c|c|c|c|c|}
\hline Pos No & $\mathrm{Cl}_{2}, \mathrm{~mm}$ & $\mathrm{Cl}_{3}, \mathrm{~mm}$ & $C l_{4}, \mathrm{~mm}$ & $\psi_{2},{ }^{\circ}$ & $\psi_{3},{ }^{\circ}$ & $\psi_{4},{ }^{\circ}$ \\
\hline 1 & \multirow{13}{*}{0.5} & \multirow{13}{*}{0.5} & \multirow{13}{*}{0.5} & 68.680 & 129.076 & 129.076 \\
\hline 2 & & & & 53.575 & 119.480 & 119.480 \\
\hline 3 & & & & 39.200 & 119.179 & 119.179 \\
\hline 4 & & & & 28.590 & 126.986 & 126.986 \\
\hline 5 & & & & 21.522 & 139.297 & 139.297 \\
\hline 6 & & & & 18.172 & 152.620 & 152.620 \\
\hline 7 & & & & 20.896 & 162.709 & 162.709 \\
\hline 8 & & & & 31.752 & 166.200 & 166.200 \\
\hline 9 & & & & 46.984 & 164.759 & 164.759 \\
\hline 10 & & & & 61.989 & 160.384 & 160.384 \\
\hline 11 & & & & 73.192 & 153.171 & 153.171 \\
\hline 12 & & & & 76.487 & 142.391 & 142.391 \\
\hline 13 & & & & 68.680 & 129.076 & 129.076 \\
\hline
\end{tabular}

\section{Equivalent Linkage}

When the continuous contact mode between journal and bearing at a joint has occurred, the clearance vector is equal to the difference between journal and bearing radii. In the presence of clearance at a revolute joint, the two kinematic constraints lost, and two degrees of freedom consisting of the horizontal and vertical displacements of the journal center relative to bearing center are added to the mechanism motion. These movements may lead to uncertainties in the motion of mechanism. So, additional constraints are necessary to analyze the kinematics of a system. 


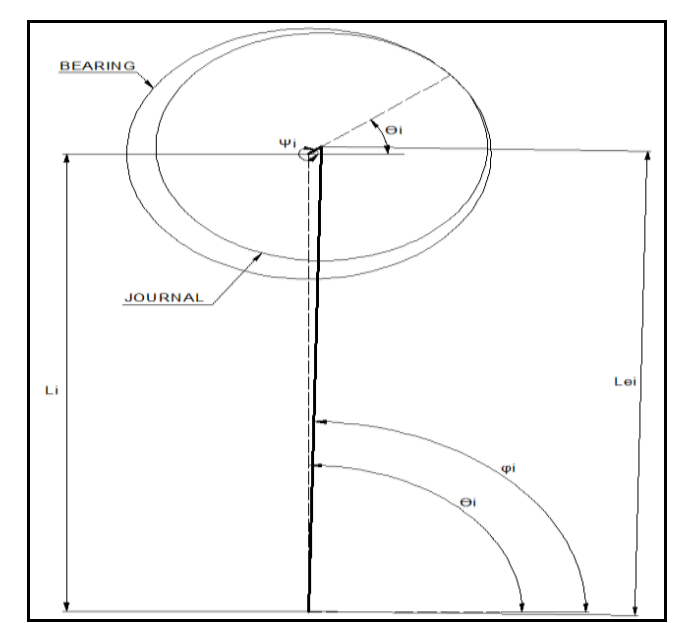

Fig-5: Linkage Parameter of 4-R mechanism with clearance at joints.

Linkage parameters of ideal mechanism are tabulated below in table-2.

Table-2 Linkage Parameters of ideal four bar mechanism in one revolution

\begin{tabular}{|c|c|c|c|c|c|c|c|c|}
\hline $\begin{array}{l}\text { Pos No } \\
\end{array}$ & $l_{l}, \mathrm{~mm}$ & $l_{2}, \mathrm{~mm}$ & $l_{3}, \mathrm{~mm}$ & $l_{4}, \mathrm{~mm}$ & $\theta_{1},{ }^{\circ}$ & $\theta_{2}, \circ$ & $\theta_{3}, \circ$ & $\theta_{4},{ }^{\circ}$ \\
\hline 1 & \multirow{13}{*}{120} & \multirow{13}{*}{250} & \multirow{13}{*}{300} & \multirow{13}{*}{400} & 0 & 248.680 & 129.076 & \multirow{13}{*}{180} \\
\hline 2 & & & & & 30 & 233.575 & 119.480 & \\
\hline 3 & & & & & 60 & 219.200 & 119.179 & \\
\hline 4 & & & & & 90 & 208.590 & 126.986 & \\
\hline 5 & & & & & 120 & 201.522 & 139.297 & \\
\hline 6 & & & & & 150 & 198.172 & 152.620 & \\
\hline 7 & & & & & 180 & 200.896 & 162.709 & \\
\hline 8 & & & & & 210 & 211.752 & 166.200 & \\
\hline 9 & & & & & 240 & 226.984 & 164.759 & \\
\hline 10 & & & & & 270 & 241.989 & 160.384 & \\
\hline 11 & & & & & 300 & 253.192 & 153.171 & \\
\hline 12 & & & & & 330 & 256.487 & 142.391 & \\
\hline 13 & & & & & 360 & 248.680 & 129.076 & \\
\hline
\end{tabular}

Equivalent linkage is the resultant vector of the nominal link and the clearance link. Equivalent link is constructed considering the clearance of $0.5 \mathrm{~mm}$ which is exaggerated clearance used for the study. Linkage parameters (i.e. equivalent link and its position) are determined and the details are given in table-3.

Table-3 Linkage Parameters of four bar mechanism with joint clearances in one revolution

\begin{tabular}{|c|c|c|c|c|c|c|c|c|}
\hline Pos No & $\boldsymbol{l}_{\boldsymbol{l}}, \mathbf{m m}$ & $\boldsymbol{l e}_{\boldsymbol{2}}, \mathbf{m m}$ & $\boldsymbol{l e}_{\boldsymbol{3}}, \mathbf{m m}$ & $\boldsymbol{l}_{\boldsymbol{4}}, \mathbf{m m}$ & $\boldsymbol{\varphi}_{\boldsymbol{l}},{ }^{\circ}$ & $\boldsymbol{\varphi}_{\boldsymbol{2}}{ }^{\circ}{ }^{\circ}$ & $\boldsymbol{\varphi}_{\boldsymbol{3}}{ }^{\circ}$ & $\boldsymbol{\varphi}_{\mathbf{4}}{ }^{\circ}$ \\
\hline 1 & 120.183 & 249.747 & 299.685 & 400 & 0.222 & 68.774 & 129.076 & 180 \\
\hline 2 & 120.458 & 249.705 & 299.754 & 400 & 30.095 & 53.618 & 119.48 & 180 \\
\hline 3 & 120.917 & 248.687 & 299.756 & 400 & 59.256 & 39.514 & 119.179 & 180 \\
\hline 4 & 120.24 & 249.427 & 299.699 & 400 & 89.791 & 28.547 & 126.986 & 180 \\
\hline 5 & 119.927 & 249.267 & 299.621 & 400 & 119.764 & 21.577 & 139.297 & 180 \\
\hline 6 & 119.667 & 249.15 & 299.556 & 400 & 149.822 & 18.221 & 152.62 & 180 \\
\hline 7 & 119.553 & 249.107 & 299.523 & 400 & 179.915 & 20.946 & 162.709 & 180 \\
\hline 8 & 119.5 & 249.15 & 299.514 & 400 & 209.976 & 31.817 & 166.2 & 180 \\
\hline 9 & 119.513 & 249.5 & 299.518 & 400 & 240.035 & 46.965 & 164.759 & 180 \\
\hline 10 & 119.559 & 249.427 & 299.529 & 400 & 270.113 & 62.078 & 160.384 & 180 \\
\hline 11 & 119.658 & 249.587 & 299.554 & 400 & 300.175 & 73.273 & 153.171 & 180 \\
\hline 12 & 119.859 & 249.705 & 299.604 & 400 & 330.229 & 76.548 & 142.391 & 180 \\
\hline 13 & 120.183 & 249.787 & 299.685 & 400 & 359.988 & 68.724 & 129.076 & 180 \\
\hline
\end{tabular}

The variation in the nominal lengths of crank, coupler and follower of an equivalent linkage are graphically shown in fig-6 to fig- 8 . Variation in nominal crank is from $0.76 \%$ minimum to $0.42 \%$ maximum. Variation in the nominal coupler is from $0.52 \%$ maximum to $0.08 \%$ minimum, similarly for the follower $0.16 \%$ maximum to $0.18 \%$ minimum. This variations obtained on the linkage parameters is much higher than tolerances provided on the linkage. 


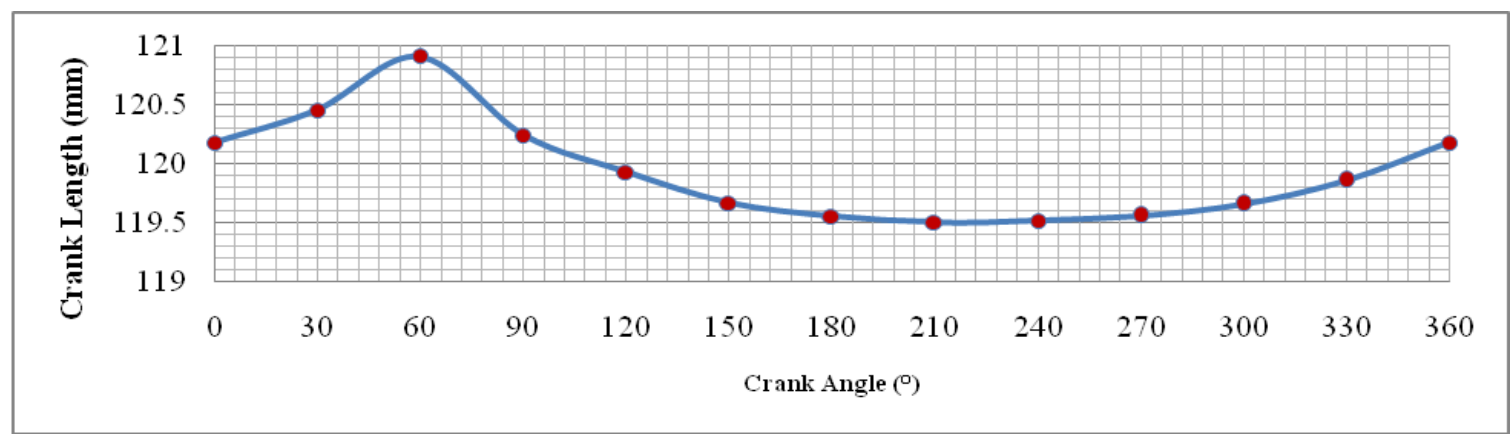

Fig-6: Variations in equivalent crank

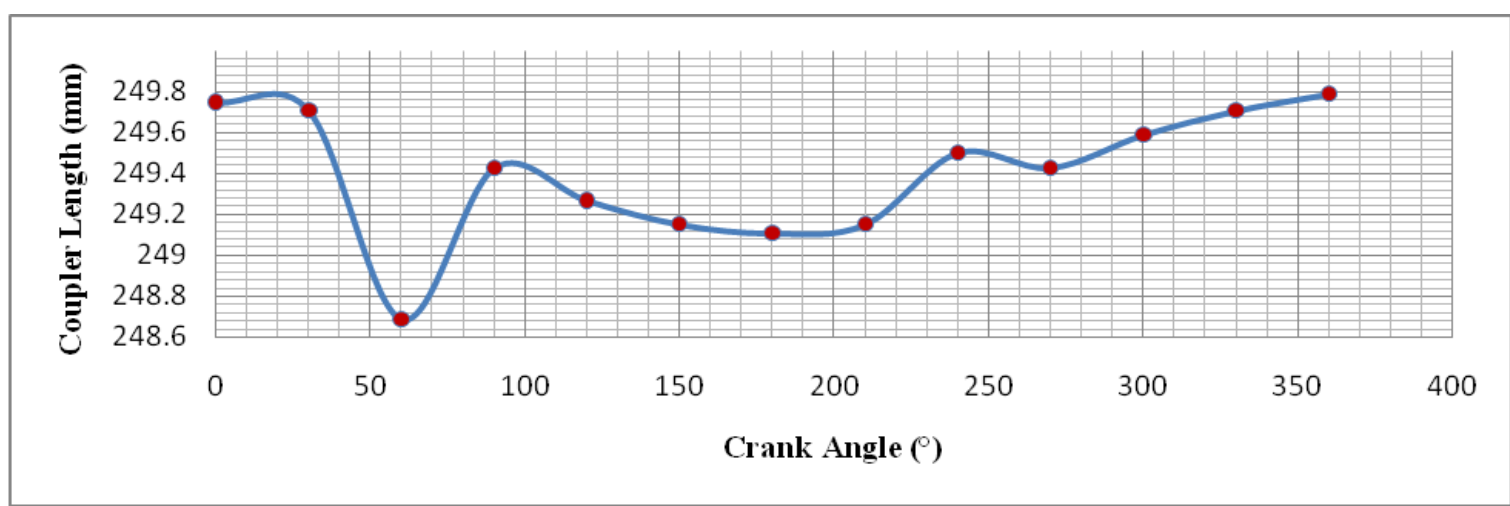

Fig-7: Variations in equivalent coupler

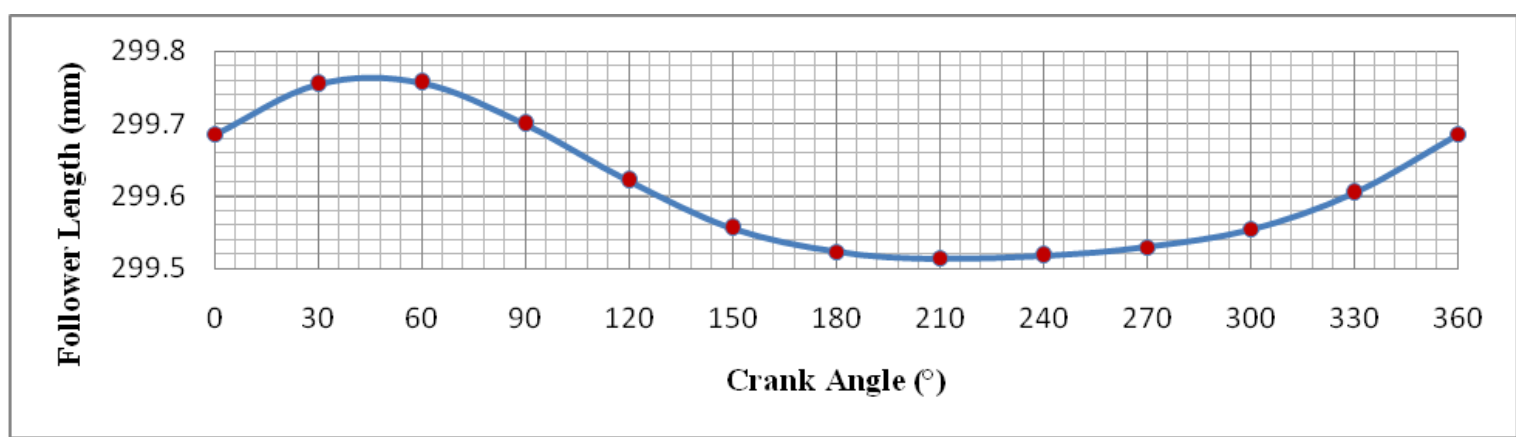

Fig-8: Variations in equivalent follower

IV. Analysis Of Four Bar Mechanism

Ideal four bar mechanism is constructed in multi-body dynamic software. Results for kinematic and dynamic analysis are extracted. Similarly, set of twelve equivalent four bar mechanisms are constructed and variations in the angular velocity, angular acceleration of links and the joint forces are recorded.

4.1 Linkage Parameters Steel is assumed as linkage material for the analysis. Material Properties are given below. Linkage mass and inertia is tabulated in table-4.

Density $(\rho) 7801 \mathrm{~kg} / \mathrm{m}^{3}$

Poisson's Ratio (v) 0.29

Young's Modulus (E) $2.07 \mathrm{E}+05 \mathrm{~N} / \mathrm{mm}^{2}$

Table-4 Linkage mass \& Inertia

\begin{tabular}{|c|c|c|c|c|}
\hline \multirow{2}{*}{ Link } & \multirow{2}{*}{ Mass (kg) } & \multicolumn{3}{|c|}{ Mass Moment of Inertia $\left(\mathbf{k g m m}^{2}\right)$} \\
\cline { 3 - 5 } & & $\boldsymbol{I}_{\boldsymbol{X}}$ & $\boldsymbol{I}_{\boldsymbol{Y}}$ & $\boldsymbol{I}_{\boldsymbol{Z}}$ \\
\hline Fixed Link & 0.408883 & 6015.3905 & 5995.2036 & 21.890611 \\
\hline Crank & 0.135848 & 227.64994 & 221.11475 & 7.1012155 \\
\hline Coupler & 0.262614 & 1602.8785 & 1590.005 & 13.967721 \\
\hline Follower & 0.311371 & 2664.1874 & 2648.8761 & 16.608684 \\
\hline
\end{tabular}

Dynamic parameters of the four bar mechanism are investigated for lower and higher crank Speed of $5 \mathrm{rpm}$ and $1500 \mathrm{rpm}$ respectively. 
4.2 Kinematic Analysis Kinematic analysis is carried out. Results of angular velocities and angular accelerations of four revolute joints are determined and the plot of angular velocity vs crank angle of ideal four bar mechanism is shown in fig-9 and fig-10. Similarly, plots of angular acceleration vs crank angle of ideal four bar mechanism shown in fig-11 and fig-12.

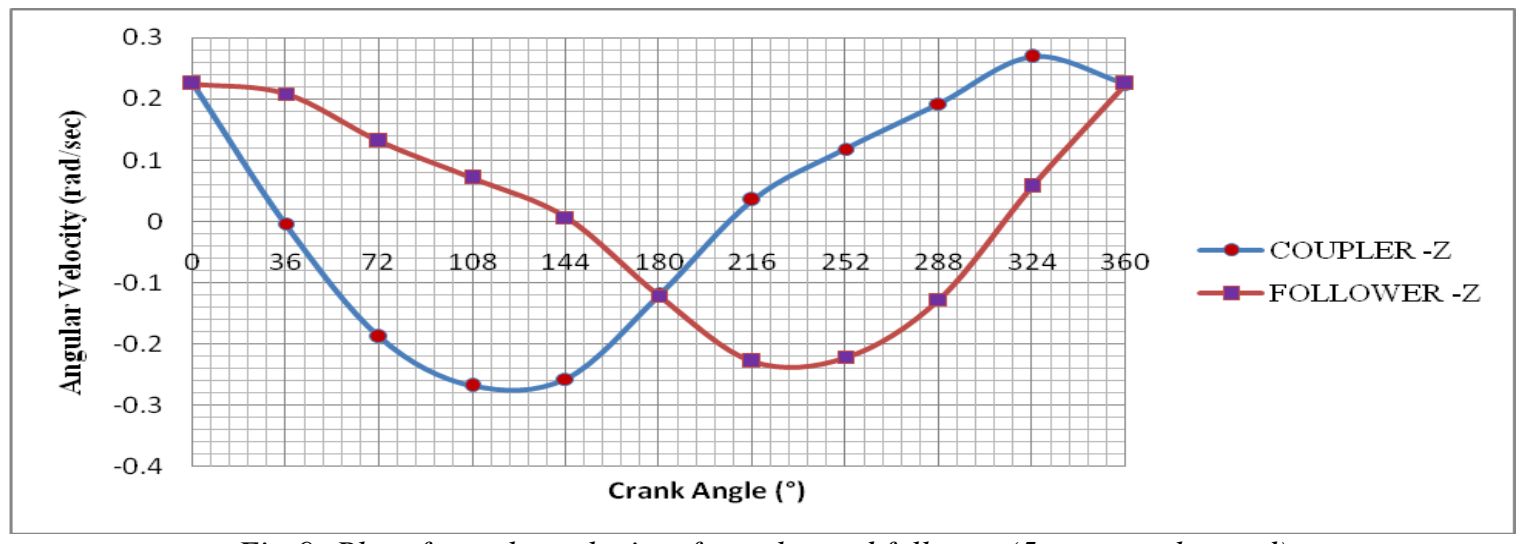

Fig-9: Plot of angular velocity of coupler and follower (5 rpm crank speed)

The angular velocity and angular acceleration of equivalent mechanism are recorded and tabulated in table- 5 and table-6. Joint between crank and coupler is denoted by Joint-2, whereas between coupler and follower and follower with the fixed link is denoted by Joint- 3 and Joint-4 respectively.

Table-5 Angular Velocity of ideal four bar mechanism ( $5 \mathrm{rpm}$ Crank Speed)

\begin{tabular}{|c|c|c|c|c|c|c|}
\hline 5 rpm Ideal & \multicolumn{7}{|c|}{ Angular Velocity (rad/sec) } \\
\hline Position, $^{\circ}$ & Coupler & Follower & Joint-1 & Joint-2 & Joint-3 & Joint-4 \\
\hline 0 & 0.2245 & 0.2245 & 0.5238 & 0.7483 & 0 & 0.2245 \\
\hline 36 & -0.0041 & 0.2081 & 0.5238 & 0.5197 & 0.2123 & 0.2081 \\
\hline 72 & -0.1885 & 0.1307 & 0.5238 & 0.3353 & 0.3192 & 0.1307 \\
\hline 108 & -0.2677 & 0.0716 & 0.5238 & 0.2561 & 0.3393 & 0.0716 \\
\hline 144 & -0.2565 & 0.0064 & 0.5238 & 0.2673 & 0.2629 & 0.0064 \\
\hline 180 & -0.1205 & -0.1212 & 0.5238 & 0.4033 & 0 & 0.1212 \\
\hline 216 & 0.0356 & -0.2279 & 0.5238 & 0.5594 & 0.2635 & 0.2279 \\
\hline 252 & 0.1177 & -0.2216 & 0.5238 & 0.6416 & 0.3394 & 0.2216 \\
\hline 288 & 0.1918 & -0.1272 & 0.5238 & 0.7156 & 0.319 & 0.1272 \\
\hline 324 & 0.2688 & 0.0572 & 0.5238 & 0.7926 & 0.2116 & 0.0572 \\
\hline 360 & 0.2238 & 0.2248 & 0.5238 & 0.7476 & 0 & 0.2248 \\
\hline Max & 0.2773 & 0.2378 & 0.524 & 0.801 & 0.341 & 0.238 \\
\hline Min & -0.275 & -0.2369 & 0.524 & 0.249 & 0 & 0.006 \\
\hline
\end{tabular}

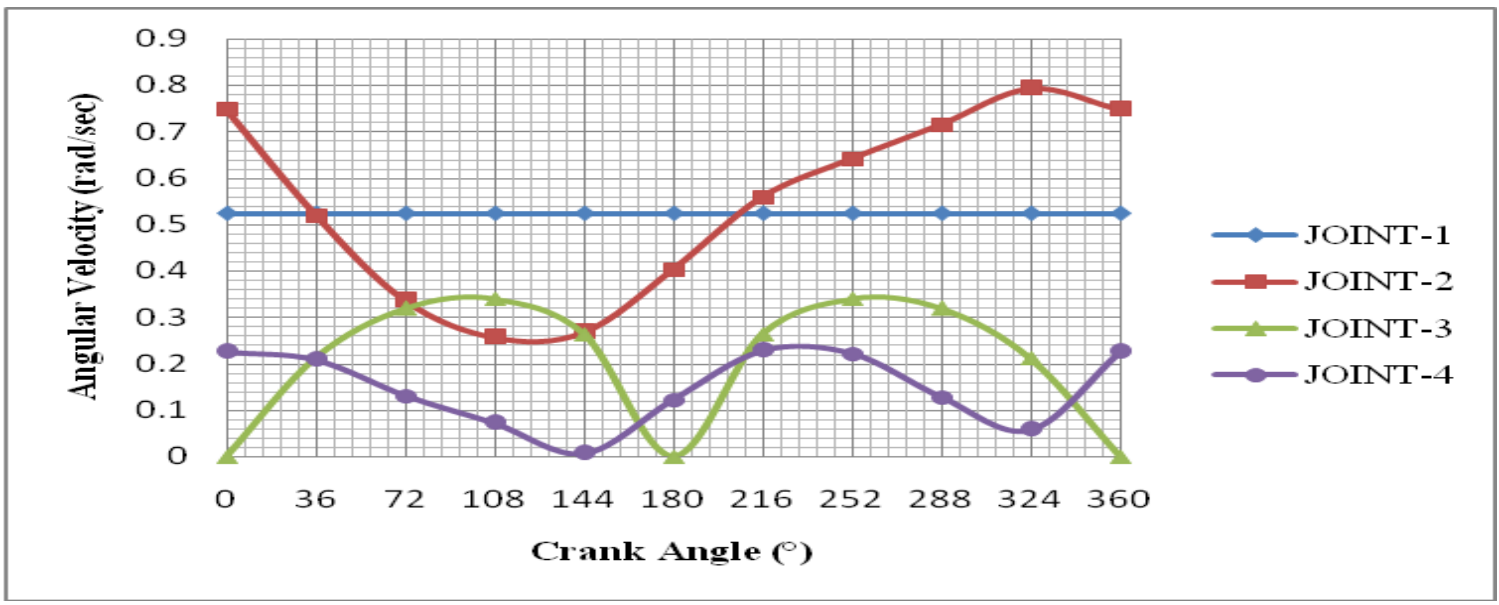

Fig-10: Plot of angular velocity of revolute joint (5rpm crank speed)

Max angular velocity of coupler is $0.2773 \mathrm{rad} / \mathrm{sec}$ and that of follower is $0.2378 \mathrm{rad} / \mathrm{sec}$. Whereas minimum angular velocity of coupler is $0.2750 \mathrm{rad} / \mathrm{sec}$ and of follower is $0.2369 \mathrm{rad} / \mathrm{sec}$. 
Table-6 Angular Acceleration of ideal four bar mechanism (5 rpm Crank Speed)

\begin{tabular}{|c|c|c|c|c|c|c|}
\hline 5 RPM Ideal & \multicolumn{7}{|c|}{ Angular Acceration (rad/sec ${ }^{2}$} \\
\hline Position, $^{\circ}$ & Coupler -Z & Follower -Z & Joint 1 & Joint 2 & Joint 3 & Joint 4 \\
\hline 0 & -0.1365 & 0.0655 & 0 & 0.1365 & 0.2019 & 0.0655 \\
\hline 36 & -0.1979 & -0.063 & 0 & 0.1979 & 0.1349 & 0.063 \\
\hline 72 & -0.1061 & -0.0572 & 0 & 0.1061 & 0.0489 & 0.0572 \\
\hline 108 & -0.0294 & -0.0452 & 0 & 0.0294 & 0.0158 & 0.0452 \\
\hline 144 & 0.0553 & -0.0733 & 0 & 0.0553 & 0.1287 & 0.0733 \\
\hline 180 & 0.1563 & -0.1273 & 0 & 0.1563 & 0.2835 & 0.1273 \\
\hline 216 & 0.0905 & -0.0375 & 0 & 0.0905 & 0.128 & 0.0375 \\
\hline 252 & 0.0581 & 0.0426 & 0 & 0.0581 & 0.0155 & 0.0426 \\
\hline 288 & 0.068 & 0.1172 & 0 & 0.068 & 0.0492 & 0.1172 \\
\hline 324 & 0.0426 & 0.178 & 0 & 0.0426 & 0.1353 & 0.178 \\
\hline 360 & -0.1372 & 0.0647 & 0 & 0.1372 & 0.2019 & 0.0647 \\
\hline Max & 0.1563 & 0.178 & 0 & 0.2071 & 0.2835 & 0.178 \\
\hline Min & -0.2071 & -0.1273 & 0 & 0.0005 & 0.0018 & 0.0013 \\
\hline
\end{tabular}

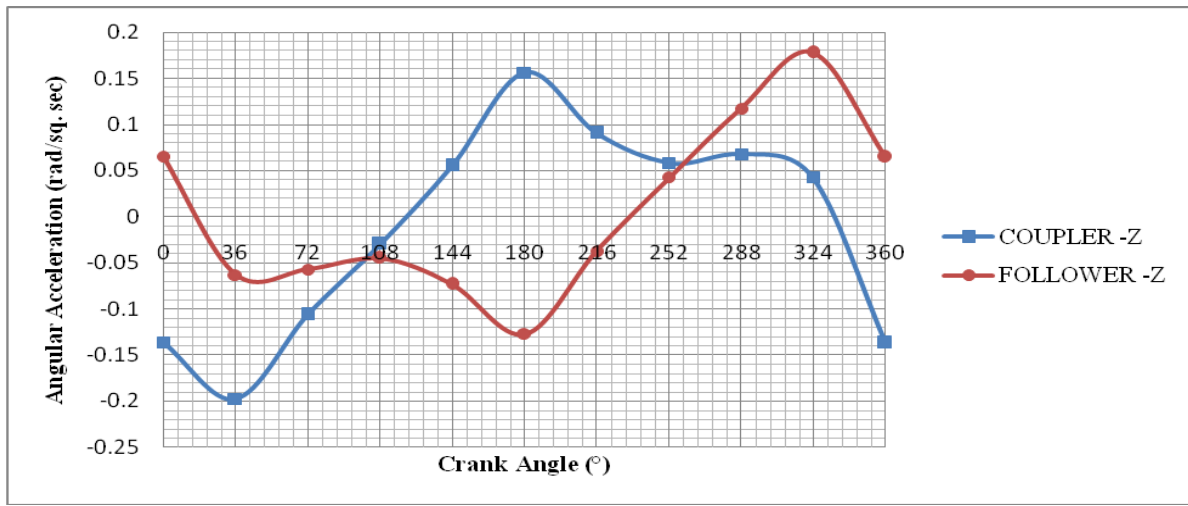

Fig-11: Plot of angular acceleration of coupler and follower (5rpm crank speed)

Max angular acceleration of coupler is $0.1563 \mathrm{rad} / \mathrm{sec}^{2}$ and of follower is $0.1780 \mathrm{rad} / \mathrm{sec}^{2}$, whereas minimum angular acceleration of coupler is $0.2071 \mathrm{rad} / \mathrm{sec}^{2}$ and of follower is $0.1273 \mathrm{rad} / \mathrm{sec}^{2}$

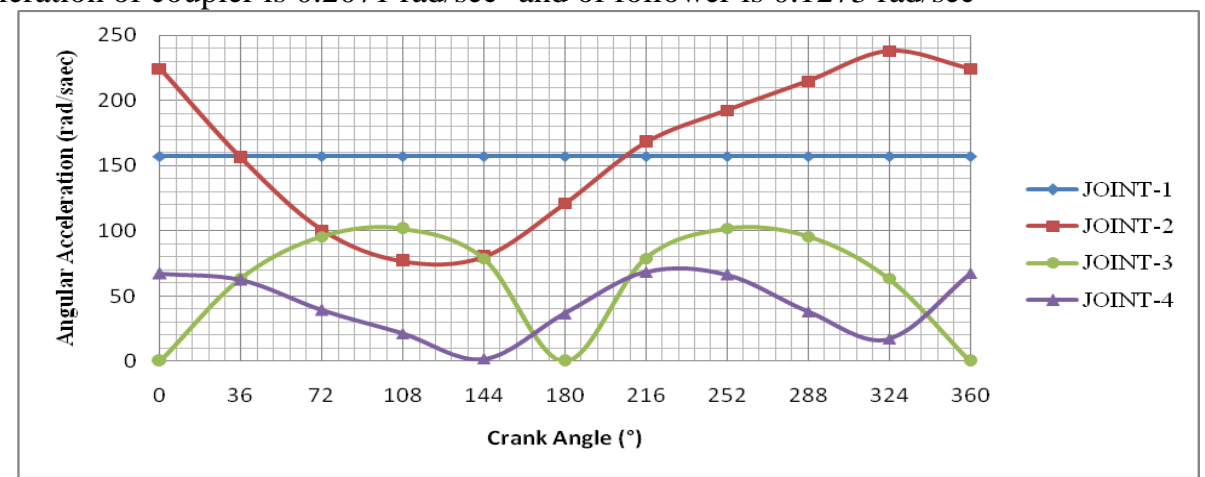

Fig-12: Plot of angular acceleration of revolute joints (5 rpm crank speed)

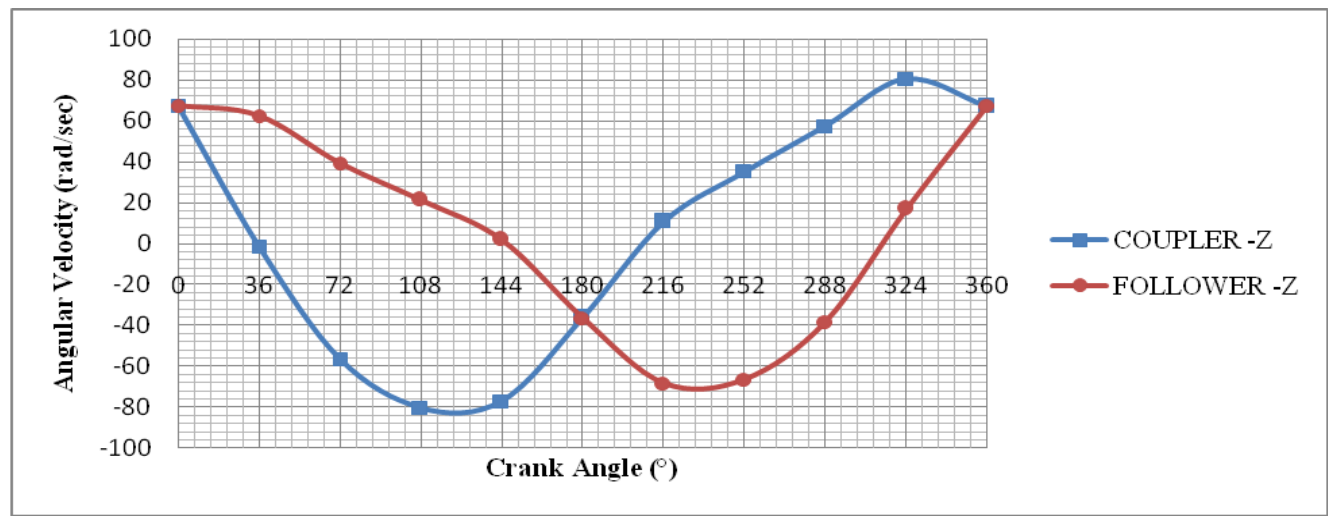

Fig-13: Plot of angular velocity of coupler and follower (1500 rpm crank speed) 
Table-7 Angular velocity of ideal four bar mechanism (1500 rpm crank speed)

\begin{tabular}{|c|c|c|c|c|c|c|}
\hline 1500 RPM Ideal & \multicolumn{7}{|c|}{ Angular Velocity (rad/sec) } \\
\hline Position, $^{\circ}$ & Coupler -z & Follower -z & Joint 1 & Joint 2 & Joint 3 & Joint 4 \\
\hline 0 & 67.3469 & 67.3469 & 157.143 & 224.4898 & 0 & 67.3469 \\
\hline 36 & -1.2402 & 62.4438 & 157.143 & 155.9027 & 63.684 & 62.4438 \\
\hline 72 & -56.5507 & 39.2099 & 157.143 & 100.5922 & 95.7606 & 39.2099 \\
\hline 108 & -80.299 & 21.4947 & 157.143 & 76.8438 & 101.794 & 21.4947 \\
\hline 144 & -76.9453 & 1.9293 & 157.143 & 80.1975 & 78.8747 & 1.9293 \\
\hline 180 & -36.1506 & -36.3559 & 157.143 & 120.9923 & 0.2053 & 36.3559 \\
\hline 216 & 10.6832 & -68.3773 & 157.143 & 167.826 & 79.0605 & 68.3773 \\
\hline 252 & 35.323 & -66.4934 & 157.143 & 192.4659 & 101.816 & 66.4934 \\
\hline 288 & 57.5385 & -38.151 & 157.143 & 214.6814 & 95.6895 & 38.151 \\
\hline 324 & 80.6485 & 17.1602 & 157.143 & 237.7913 & 63.4883 & 17.1602 \\
\hline 360 & 67.1487 & 67.4412 & 157.143 & 224.2916 & 0.2925 & 67.4412 \\
\hline Max & 80.6485 & 67.4412 & 157.143 & 237.7913 & 101.816 & 68.3773 \\
\hline Min & -80.299 & -68.3773 & 157.143 & 76.8438 & 0.2053 & 1.9293 \\
\hline
\end{tabular}

Maximum and minimum angular velocity plot of coupler and follower at constant crank speed of $1500 \mathrm{rpm}$ is shown in fig-13 and plot of angular velocity of revolute joint is shown in fig-14. Maximum angular velocity of coupler is $80.6485 \mathrm{rad} / \mathrm{sec}$ and of follower is $67.4412 \mathrm{rad} / \mathrm{sec}$ and minimum angular velocity of coupler is $80.299 \mathrm{rad} / \mathrm{sec}$ of follower is $68.3773 \mathrm{rad} / \mathrm{sec}$. Angular velocity and angular acceleration of coupler; follower and all four revolute joints are tabulated in table-7 and table-8. Plot of angular acceleration is shown in fig- 15 .

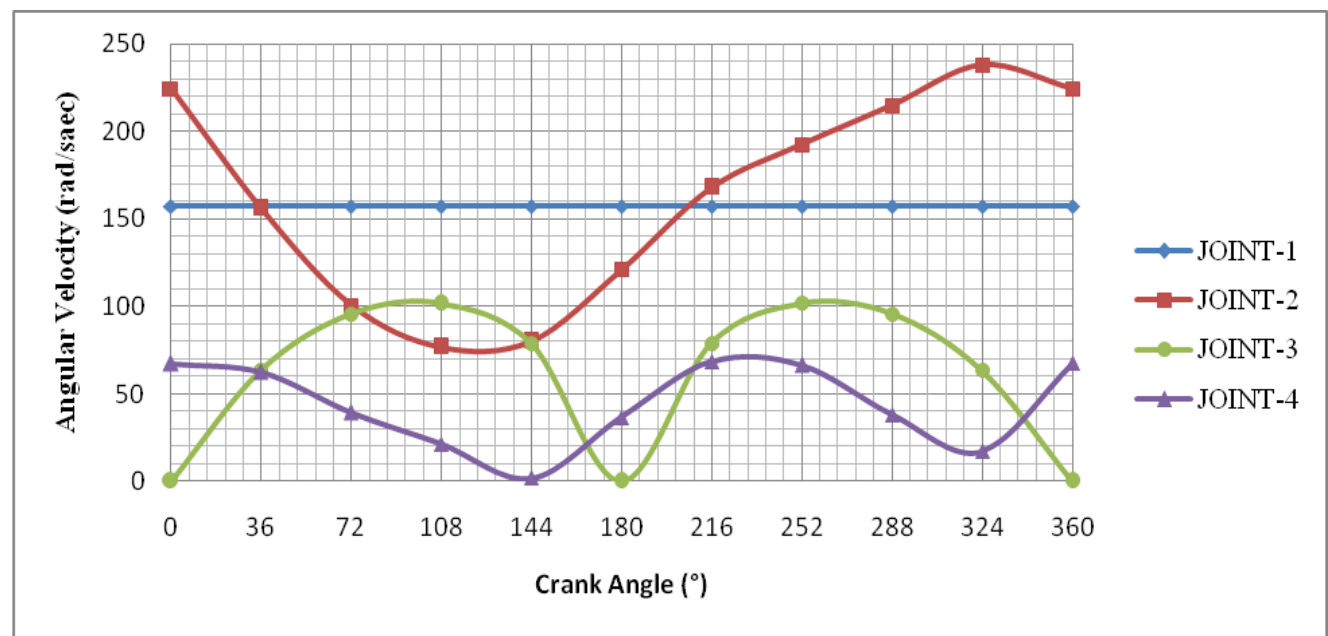

Fig-14: Plot of angular velocity of revolute joint (1500 rpm crank speed)

Table-8 Angular acceleration of ideal four bar mechanism (1500 rpm crank speed)

\begin{tabular}{|c|c|c|c|c|c|c|}
\hline 1500 RPM Ideal & \multicolumn{7}{|c|}{ Angular Acceleration (rad/sec ${ }^{2}$ ) } \\
\hline Position, $^{\circ}$ & Coupler -z & Follower -z & Joint 1 & Joint 2 & Joint 3 & Joint 4 \\
\hline 0 & -12281.26 & 5892.2116 & 0 & 12281.26 & 18173.472 & 5892.2116 \\
\hline 36 & -17809.6841 & -5668.0411 & 0 & 17809.684 & 12141.643 & 5668.0411 \\
\hline 72 & -9549.8262 & -5145.0176 & 0 & 9549.8262 & 4404.8086 & 5145.0176 \\
\hline 108 & -2649.9623 & -4068.4178 & 0 & 2649.9623 & 1418.4556 & 4068.4178 \\
\hline 144 & 4980.1187 & -6598.6945 & 0 & 4980.1187 & 11578.813 & 6598.6945 \\
\hline 180 & 14062.8959 & -11455.7728 & 0 & 14062.896 & 25518.669 & 11455.773 \\
\hline 216 & 8141.476 & -3374.8853 & 0 & 8141.476 & 11516.361 & 3374.8853 \\
\hline 252 & 5224.8044 & 3832.3484 & 0 & 5224.8044 & 1392.456 & 3832.3484 \\
\hline 288 & 6117.8017 & 10547.6119 & 0 & 6117.8017 & 4429.8102 & 10547.612 \\
\hline 324 & 3837.8292 & 16015.5853 & 0 & 3837.8292 & 12177.756 & 16015.585 \\
\hline 360 & -12352.1408 & 5821.1997 & 0 & 12352.141 & 18173.341 & 5821.1997 \\
\hline Max & 14062.8959 & 16015.5853 & 0 & 17809.684 & 25518.669 & 16015.585 \\
\hline Min & -17809.6841 & -11455.7728 & 0 & 2649.9623 & 1392.456 & 3374.8853 \\
\hline
\end{tabular}




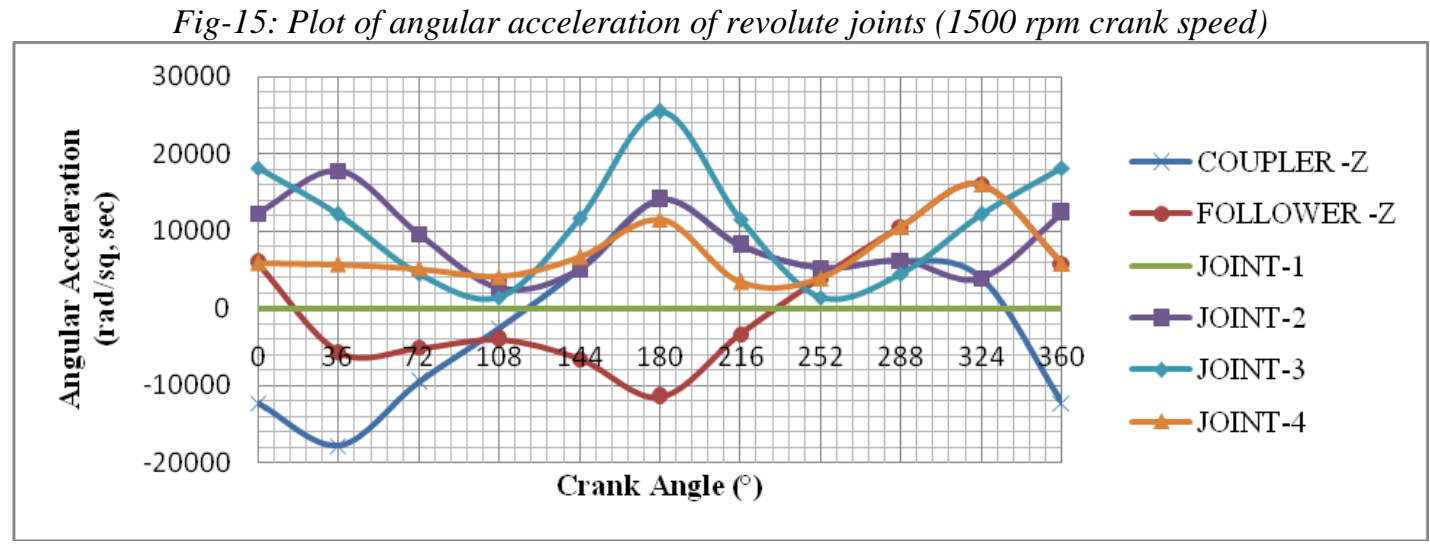

Table-9 Variation of angular velocity of four bar mechanism ( 5 rpm crank speed)

\begin{tabular}{|c|c|c|c|c|c|c|}
\hline \multirow{2}{*}{ Position, ${ }^{\circ}$} & Coupler & Follower & Joint 1 & Joint 2 & Joint 3 & Joint 4 \\
\hline Ideal & 83.195 & 71.333 & 157.14 & 240.34 & 102.43 & 71.333 \\
\hline \multicolumn{7}{|c|}{ Four bar mechanism with clearance joint } \\
\hline 0 & 83.53 & 71.4948 & 157.14 & 240.67 & 102.48 & 71.495 \\
\hline 30 & 83.849 & 71.7689 & 157.14 & 240.99 & 102.91 & 71.769 \\
\hline 60 & 84.498 & 72.0782 & 157.14 & 241.64 & 103.89 & 72.078 \\
\hline 90 & 83.698 & 71.6111 & 157.14 & 240.84 & 103.07 & 71.611 \\
\hline 120 & 83.46 & 71.1929 & 157.14 & 240.84 & 103.07 & 71.611 \\
\hline 150 & 83.136 & 70.9717 & 157.14 & 240.28 & 102.44 & 70.972 \\
\hline 180 & 83.074 & 71.0298 & 157.14 & 240.22 & 102.35 & 71.03 \\
\hline 210 & 83.146 & 71.0645 & 157.14 & 240.29 & 102.31 & 71.065 \\
\hline 240 & 83.08 & 71.1371 & 157.14 & 240.22 & 102.37 & 71.137 \\
\hline 270 & 83.16 & 71.0349 & 157.14 & 240.3 & 102.2 & 71.035 \\
\hline 300 & 83.119 & 70.9498 & 157.14 & 240.26 & 102.2 & 70.95 \\
\hline 330 & 83.109 & 71.1705 & 157.14 & 240.25 & 102.27 & 71.171 \\
\hline 360 & 83.466 & 71.5365 & 157.14 & 240.61 & 102.65 & 71.537 \\
\hline Max & 84.498 & 72.0782 & 157.14 & 241.64 & 103.89 & 72.078 \\
\hline Min & 83.074 & 70.9498 & 157.14 & 240.22 & 102.2 & 70.95 \\
\hline
\end{tabular}

Twelve crank positions of four bar mechanism with three clearance revolute joints are analyzed. The variations in angular velocity of coupler and follower are observed $1.59 \%$ and $1.05 \%$ respectively for slower crank speed of $5 \mathrm{rpm}$. Angular velocity of coupler and follower, for higher crank speed of $1500 \mathrm{rpm}$ has variations of $1.57 \%$ and $1.04 \%$. The variations in maximum angular velocity of coupler, follower and joints at constant crank speed of $5 \mathrm{rpm}$ are shown in fig-16 to fig-18, which is tabulated at table- 9 .

Similarly, variations of angular velocity of coupler, follower and revolute joints of four bar mechanism at constant crank speed of $1500 \mathrm{rpm}$ is shown in fig-19 to fig-21, respective data is placed at table- 10 .

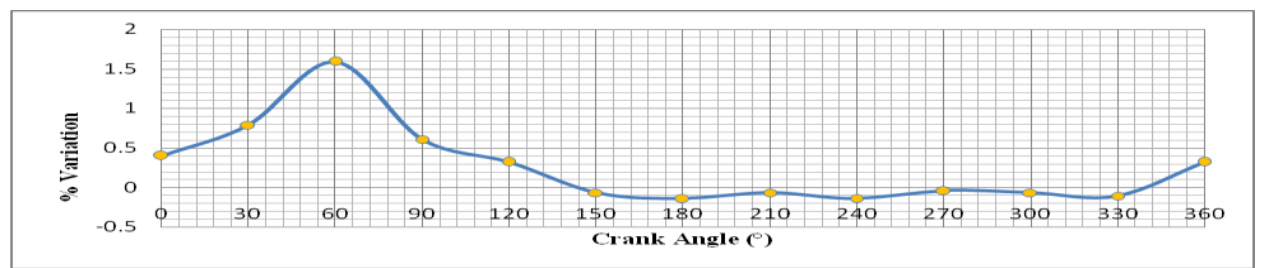

Fig-16: Plot of variation in maximum angular velocity of coupler (5 rpm crank speed)

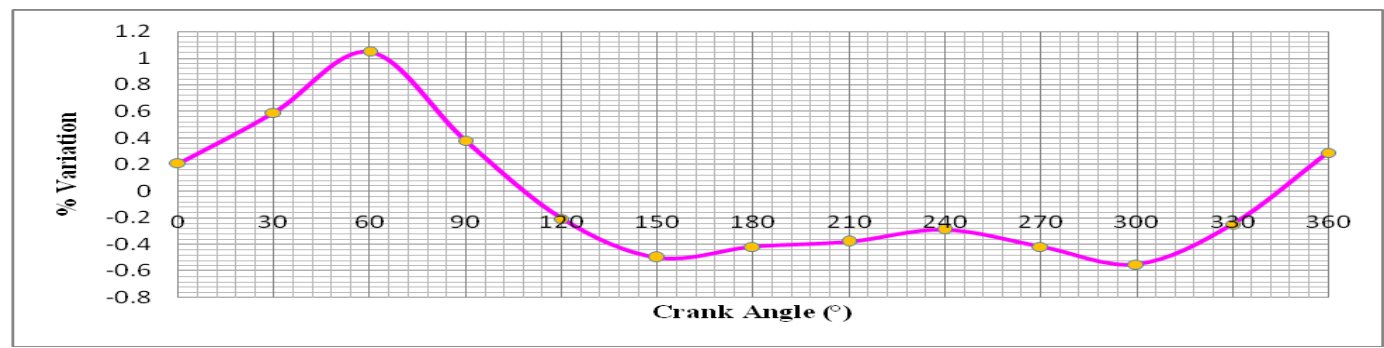

Fig-17: Plot of variation in maximum angular velocity of follower (5 rpm crank speed) 


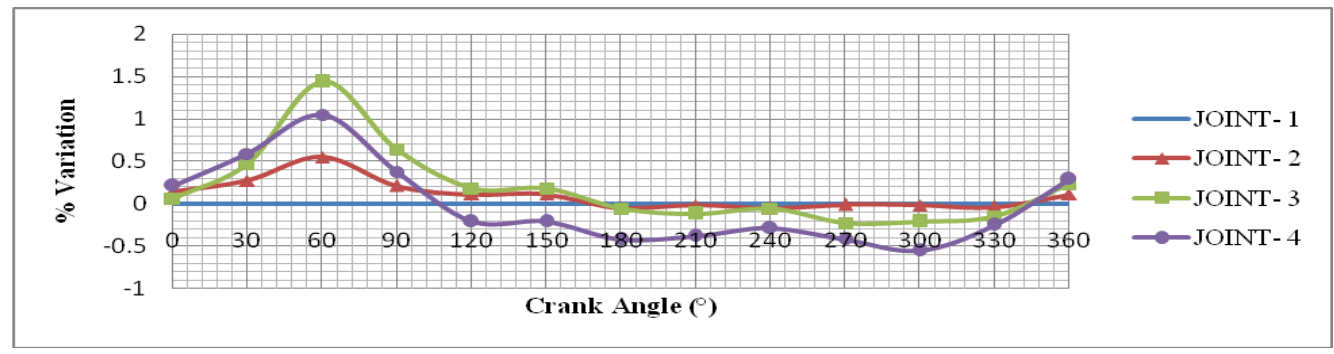

Fig-18: Plot of percentage variation in maximum joint velocity (crank speed 5 rpm)

Table-10 Variation of angular velocity of four bar mechanism (1500 rpm crank speed)

\begin{tabular}{|c|c|c|c|c|c|c|}
\hline \multirow{2}{*}{ Position } & \multicolumn{7}{|c|}{ Max Angular Velocity (rad/sec) } \\
\cline { 2 - 7 } & Coupler & Follower & Joint 1 & Joint 2 & Joint 3 & Joint 4 \\
\hline 1500 rpm Ideal & 83.1951 & 71.333 & 157.143 & 240.338 & 102.432 & 71.333 \\
\hline \multicolumn{7}{|c|}{ Four Bar Mechanism With Clearance at Revolute Joint } \\
\hline 0 & 83.5298 & 71.4948 & 157.143 & 240.673 & 102.477 & 71.495 \\
\hline 30 & 83.8487 & 71.7689 & 157.143 & 240.992 & 102.912 & 71.769 \\
\hline 60 & 84.4983 & 72.0782 & 157.143 & 241.641 & 103.891 & 72.078 \\
\hline 90 & 83.6979 & 71.6111 & 157.143 & 240.841 & 103.067 & 71.611 \\
\hline 120 & 83.4598 & 71.1929 & 157.143 & 240.841 & 103.067 & 71.611 \\
\hline 150 & 83.1359 & 70.9717 & 157.143 & 240.279 & 102.441 & 70.972 \\
\hline 180 & 83.0741 & 71.0298 & 157.143 & 240.217 & 102.348 & 71.03 \\
\hline 210 & 83.1457 & 71.0645 & 157.143 & 240.289 & 102.313 & 71.065 \\
\hline 240 & 83.0803 & 71.1371 & 157.143 & 240.223 & 102.373 & 71.137 \\
\hline 270 & 83.1604 & 71.0349 & 157.143 & 240.303 & 102.196 & 71.035 \\
\hline 300 & 83.1193 & 70.9498 & 157.143 & 240.262 & 102.203 & 70.95 \\
\hline 330 & 83.1088 & 71.1705 & 157.143 & 240.252 & 102.272 & 71.171 \\
\hline 360 & 83.4657 & 71.5365 & 157.143 & 240.609 & 102.65 & 71.537 \\
\hline MAX & 84.4983 & 72.0782 & 157.143 & 241.641 & 103.891 & 72.078 \\
\hline MIN & 83.0741 & 70.9498 & 157.143 & 240.217 & 102.196 & 70.95 \\
\hline \multicolumn{7}{|c|}{}
\end{tabular}

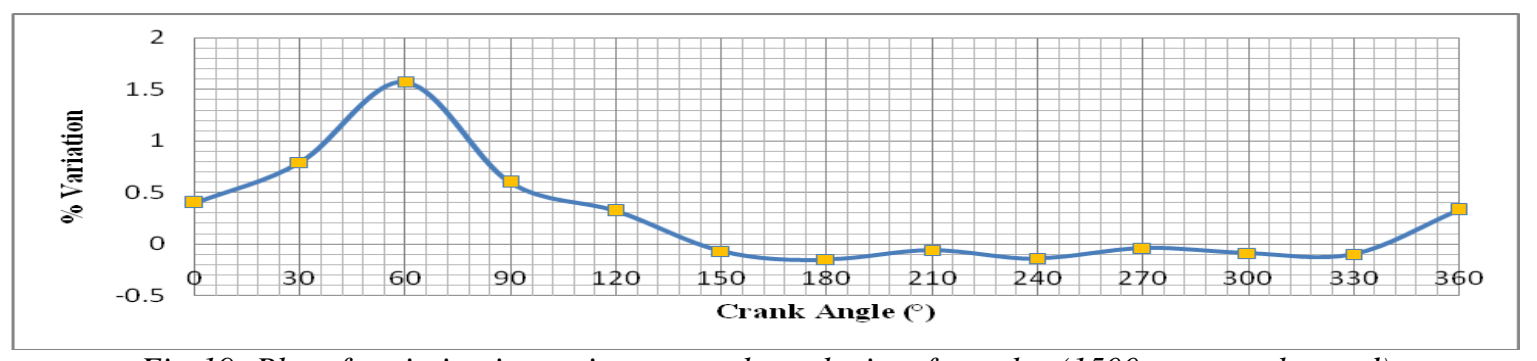

Fig-19: Plot of variation in maximum angular velocity of coupler (1500 rpm crank speed)

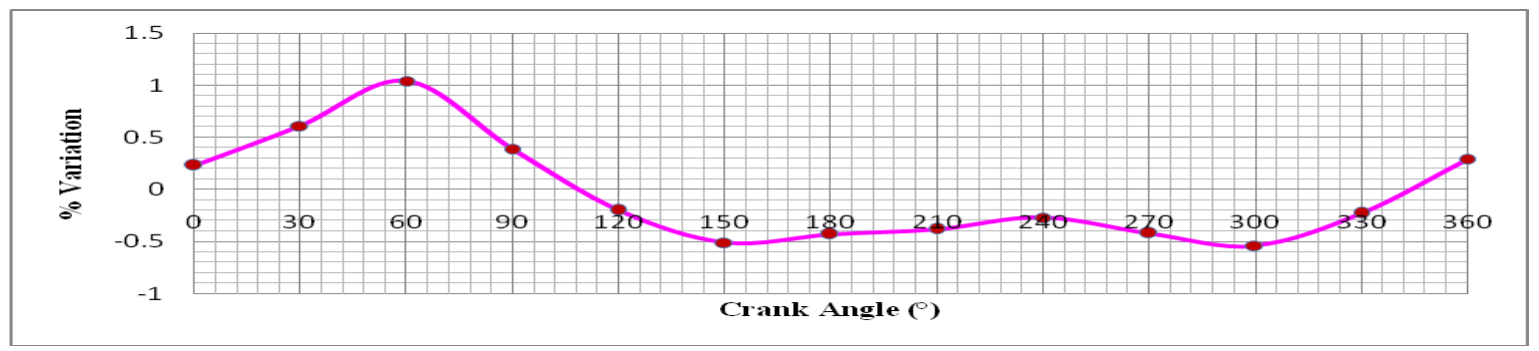

Fig-20: Plot of variation in maximum angular velocity of follower (1500 rpm crank speed)

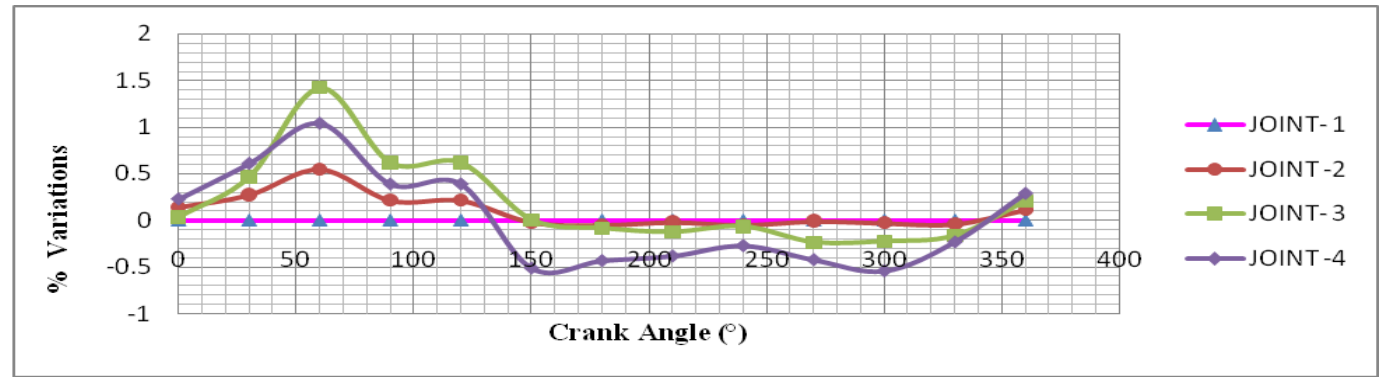

Fig-21: Plot of percentage variation in maximum joint velocity (crank speed $1500 \mathrm{rpm}$ ) 
4.3 Dynamic Analysis A mechanism is constructed in ADAMS multi body dynamic analysis software for twelve crank positions of the equivalent linkage parameters, which are investigated from CAD simulation of clearance joints. Joint forces are determined for the $90^{\circ}$ crank position, form the dynamic analysis of a ideal four bar mechanism with joint clearance.
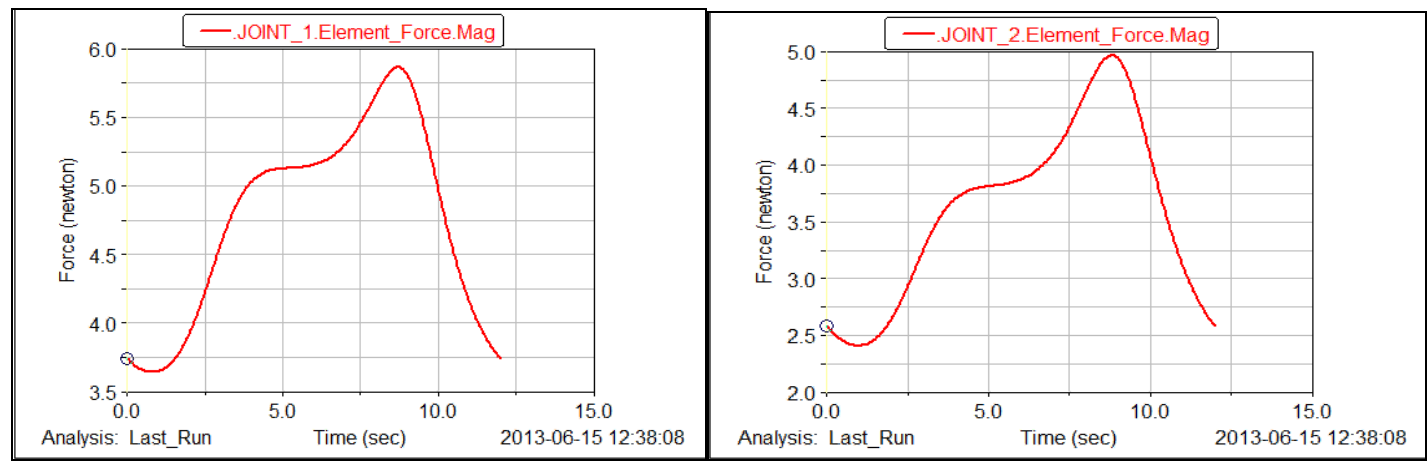

Fig-22: Element force at joint 1 and joint 2 for the equivalent linkage.

The plot of Force vs Crank angle is given in Fig-22 to Fig-23. The maximum force at joint 1 to 4 is 5.883, $4.9967,4.0788$ and 4.9696 respectively. Similarly the joint forces are obtained for set of equivalent mechanism and the results are tabulated in table-11 and table-12 for constant angular crank speed of $5 \mathrm{rpm}$ and $1500 \mathrm{rpm}$ respectively.

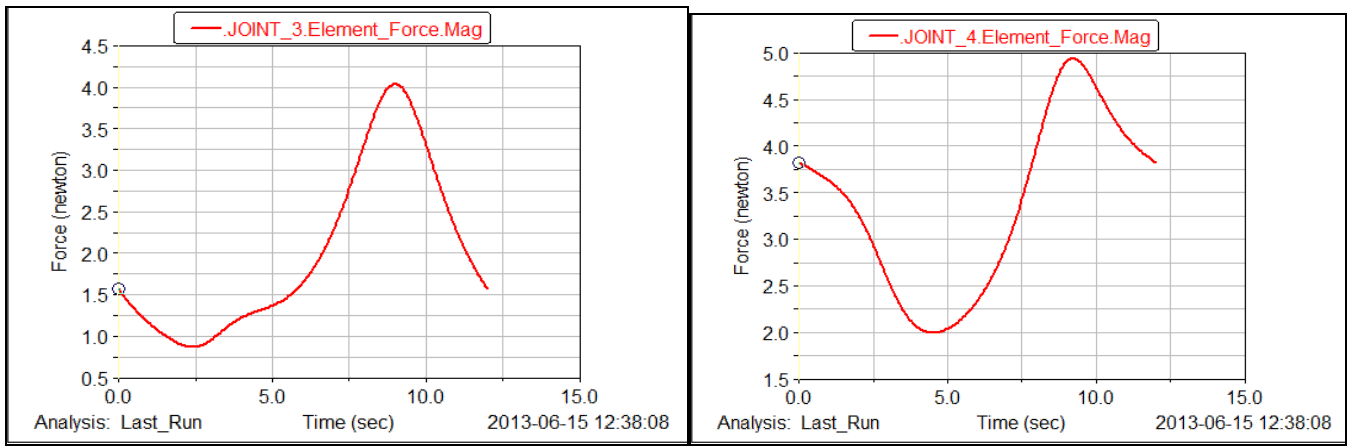

Fig-23: Element force at Joint 2 for the equivalent linkage.

The variations of joint forces for constant crank speed of $5 \mathrm{rpm}$ are shown in fig-24 and for constant crank speed of $1500 \mathrm{rpm}$ are shown in fig-25. Percentage contribution of three clearance joints on the joint forces is $1.68 \%, 1.98 \%, 3.33 \%$ and $2.19 \%$ on joint- 1 to joint- 4 respectively, for constant crank speed of 5 rpm. For higher crank speed of $1500 \mathrm{rpm}$ it is $0.58 \%, 0.61 \%, 8.88 \%$ and $7.67 \%$. An obtained result shows that the influence of clearance joints on joint forces is much higher on joint-3, i.e. the joint between coupler and follower, which degrades the performance of the mechanism.

Table-11 Variation of joint forces of four bar mechanism (5 rpm crank speed)

\begin{tabular}{|c|c|c|c|c|}
\hline \multirow{2}{*}{ Position } & \multicolumn{5}{|c|}{ Variation Max Joint Force (N) } \\
\cline { 2 - 5 } & Joint 1 & Joint 2 & Joint 3 & Joint 4 \\
\hline Ideal & 5.8835 & 4.9895 & 4.0722 & 4.9639 \\
\hline \multicolumn{5}{|c|}{ Four Bar Mechanism with Clearance at Revolute Joint } \\
\hline 0 & 5.878 & 4.9804 & 4.0613 & 4.9538 \\
\hline 30 & 5.9092 & 5.0101 & 4.1043 & 4.9907 \\
\hline 60 & 5.9782 & 5.0883 & 4.2081 & 5.073 \\
\hline 90 & 5.9242 & 5.0403 & 4.1306 & 5.0172 \\
\hline 120 & 5.8838 & 5.0008 & 4.079 & 4.964 \\
\hline 150 & 5.8743 & 4.9893 & 4.0704 & 4.958 \\
\hline 180 & 5.8723 & 4.9819 & 4.0663 & 4.9565 \\
\hline 210 & 5.871 & 4.9742 & 4.0617 & 4.9548 \\
\hline 240 & 5.8774 & 4.9832 & 4.0692 & 4.9657 \\
\hline 270 & 5.8622 & 4.9718 & 4.0407 & 4.9409 \\
\hline 300 & 5.8547 & 4.9693 & 4.0413 & 4.936 \\
\hline 330 & 5.8624 & 4.9703 & 4.0458 & 4.9406 \\
\hline 360 & 5.8919 & 4.9979 & 4.0845 & 4.9736 \\
\hline MAX & 5.9782 & 5.0883 & 4.2081 & 5.073 \\
\hline MIN & 5.8547 & 4.9693 & 4.0407 & 4.936 \\
\hline
\end{tabular}


Table-12 Variation of joint forces of four bar mechanism (1500 rpm crank speed)

\begin{tabular}{|c|c|c|c|c|}
\hline \multirow{2}{*}{ Position } & \multicolumn{4}{|c|}{ Variation in Max Joint Force (N) } \\
\cline { 2 - 5 } Ideal & Joint 1 & Joint 2 & Joint 3 & Joint 4 \\
\hline \multicolumn{5}{|c|}{ Four Bar Mechanism with Clearance at Revolute Joint } \\
\hline 0 & 1804.1845 & 1605.7674 & 851.6536 & 754.1093 \\
\hline 30 & 1805.7451 & 1605.8271 & 877.3989 & 771.3577 \\
\hline 60 & 1809.5545 & 1611.0951 & 933.2058 & 818.2397 \\
\hline 90 & 1799.61 & 1604.2774 & 901.3681 & 789.2088 \\
\hline 120 & 1796.466 & 1600.9672 & 874.0738 & 766.4856 \\
\hline 150 & 1790.5237 & 1594.7603 & 863.5318 & 760.8915 \\
\hline 180 & 1786.1031 & 1589.7507 & 854.2343 & 756.3564 \\
\hline 210 & 1781.1748 & 1584.2066 & 854.5181 & 750.0616 \\
\hline 240 & 1779.6296 & 1587.3277 & 865.8128 & 751.1685 \\
\hline 270 & 1786.5596 & 1592.923 & 857.1999 & 747.0578 \\
\hline 300 & 1792.1692 & 1597.0943 & 853.0632 & 747.5298 \\
\hline 330 & 1797.8393 & 1601.1701 & 849.8643 & 748.6411 \\
\hline 360 & 1803.0574 & 1604.6875 & 863.1448 & 765.631 \\
\hline Max & 1809.5545 & 1611.0951 & 933.2058 & 818.2397 \\
\hline Min & 1779.6296 & 1584.2066 & 849.8643 & 747.0578 \\
\hline
\end{tabular}

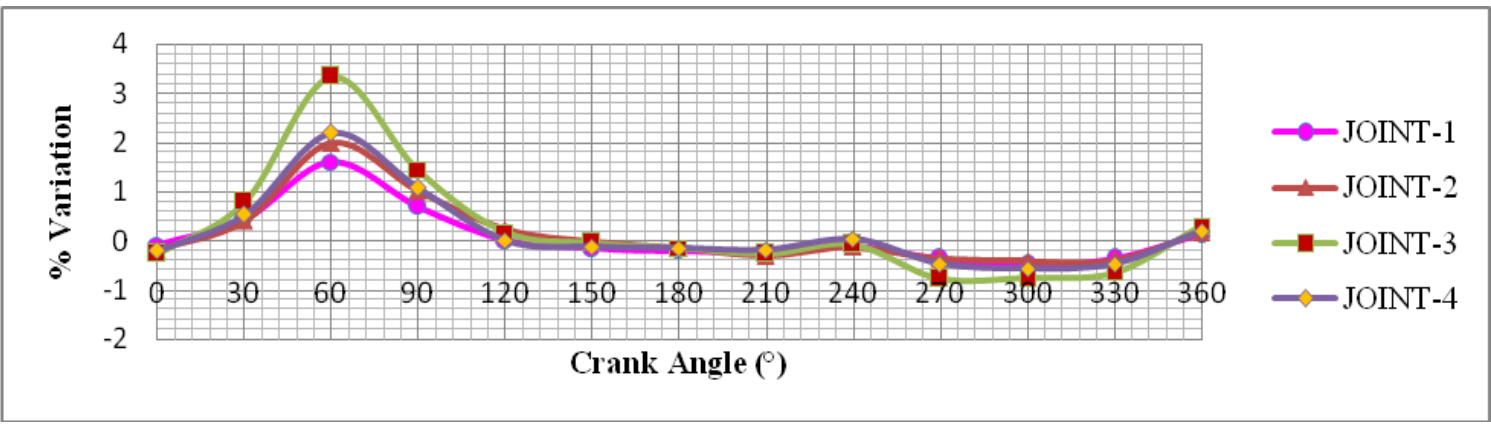

Fig-24: Percentage variation of maximum joint force (5 rpm crank speed)

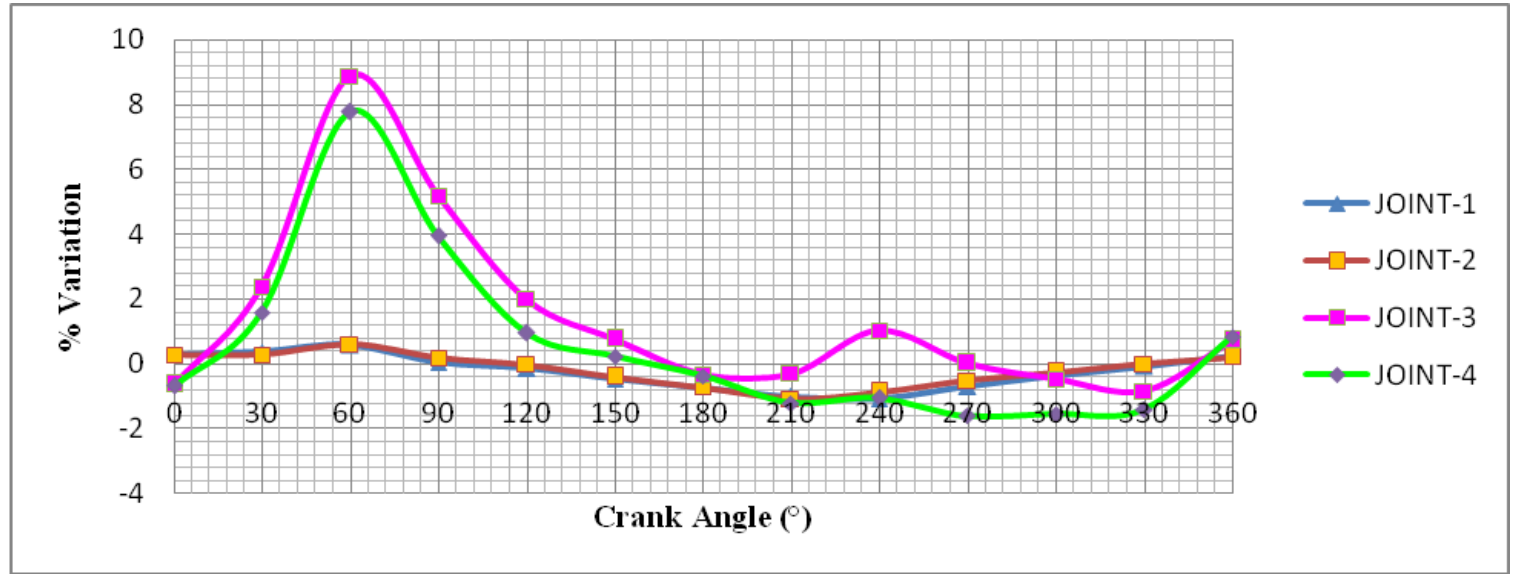

Fig-25: Percentage variation of maximum joint force (1500 rpm crank speed)

\section{Conclusion}

Presence of clearance in the joint leads to instantaneous change in the point of contact between pin and hole at each joint. A four bar mechanism was simulated with the three clearance joints. Surface contact is considered at each joint. Radial clearance $(0.5 \mathrm{~mm})$ at each joint forms a clearance link which is considered as mass-less link. Equivalent linkage was developed by virtue of clearance link causes variations in the link length which are $0.76 \%$ for crank, $0.53 \%$ for coupler and $0.12 \%$ for follower link. Similarly, variation in max angular velocity of coupler is $1.59 \%$ for constant crank speed of $5 \mathrm{rpm}$ and variation in max angular velocity of joint-3 is $1.44 \%$ for constant crank speed of $5 \mathrm{rpm}$.

Variations were investigated for higher crank speed of $1500 \mathrm{rpm}$. Angular velocity of coupler considering joint clearance is $1.57 \%$ for constant crank speed of $1500 \mathrm{rpm}$ and max angular velocity of Joint-3 considering joint clearance is $1.42 \%$. Considering pure contact, there is an effect of joint clearance on slower 
speed mechanism also. Contribution of joint forces on the mechanism varies from $3.334 \%$ to $8.882 \%$ for slower speed mechanism and higher speed mechanism which degrades the performance of mechanism.

\section{References}

[1] Kwun-Lon Tinga, Jianmin Zhua, Derek Watkins, The effects of joint clearance on position and orientation deviation of linkages and manipulators, Mechanism and Machine Theory, Vol-35, 2000, pp 391-401

[2] Selçuk Erkaya, Ibrahim Uzmay, Investigation on effect of joint clearance on dynamics of four-bar mechanism, Nonlinear Dynamics, Vol- 58, 2009, pp 179-198

[3] R. S. Haines, A theory of contact loss at revolute joint with clearance, Journal Mechanical Engineering science, Vol-22 No.3, 1980, pp 129-135.

[4] Hiroaki Funabashi, Kiyoshi Ogawa, Mikio Horie, A dynamic analysis of mechanism with clearances, Bulletin of JSME, Volume 21, No. 161, Nov 1978, pp 1653-1659.

[5] Mikio Horie, Hiroaki Funabashi, Kiyoshi Ogawa, Yasuo Naito, Naoki Shoji, A kineto-elasodynamic analysis of planer link mechanisms with consideration of bearing clearances., Bulletin of JSME, Volume 29, No. 252, June 1986, pp 1881-1887.

[6] Flores P., Lankarani H. M., Dynamic response of multi-body systems with multiple clearance joints, ASME journal of computational and nonlinear dynamics, Volume 7(3), Year 2012, PP 1-26. K7

[7] A.F. Haroun, S.M. Megahed, Simulation and Experimentation of Multi-body mechanical Systems with Clearance Revolute Joints, International journal on Mechanical and Aerospace Engineering, Volume 6, Year 2012, PP 367-376 k26

[8] A.M. Vaidya, P.M. Padole, A performance evaluation of four bar mechanism considering flexibility of links and joint stiffness, The open mechanical engineering Journal, Volume 04, Year 2010, PP 16-28. K38

[9] Wiesaaw KrasoE, Jerzy Maaachowski, Jakub Soatysiuk, Numerical investigation of a landing gear system with pin joints operating clearance, Journal of KONES Power train and Transport, Volume 17 No 2, Year 2010, PP 240-248. K6

[10] Saad Mukras, Nam H. Kim, Nathan A. Mauntler, Tony L. Schmitz, W. Gregory Sawyer, Analysis of planar multi-body systems with revolute joint wear, Wear, Volume 268, Year 2010, PP 643-652. K29

[11] P.Flores, Modeling and simulation of wear in revolute clearance joints in multi-body systems, Mechanism and Machine Theory, Volume 44, 2009, PP 1211-1222. K28

[10] A. L. Schwab, J.P. Meijaard, P. Meijers, A comparison of revolute joint clearance models in the dynamic analysis of rigid and elastic mechanical systems, Mechanism and Machine Theory, Volume 37, Year 2002, PP 895-913. K8

[13] George Sandor, Ari Erdman, Advanced Mechanism Design: Analysis and Synthesis Vol. II, pp 516-518.

[14] Saad Mukras, Dynamic modeling of a slider-crank mechanism under joint wear, Proceedings of the 32nd Annual Mechanism and Robotics Conference, IDETC August 2008, PP 1-10. K27 